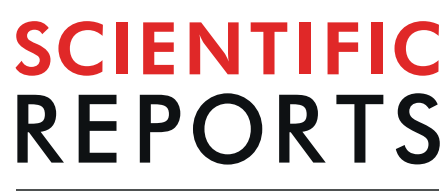

natureresearch

\title{
Nutrient availability affects the polar lipidome of Halimione portulacoides leaves cultured in hydroponics
}

\author{
Marco Custódio $\mathbb{1}^{1 *}$, Elisabete Maciel ${ }^{1,2,3}$, Maria Rosário Domingues ${ }^{2,3}$, Ana Isabel Lillebø ${ }^{1}$ \& \\ Ricardo Calado ${ }^{1^{*}}$
}

Halophytes are increasingly regarded as suitable extractive species and co-products for coastal Integrated Multi-Trophic Aquaculture (IMTA) and studying their lipidome is a valid means towards their economic valorization. Halimione portulacoides (L.) Aellen edible leaves are rich in functional lipids with nutraceutical and pharmaceutical relevance and the present study aimed to investigate the extent to which its lipidome remains unchanged under a range of dissolved inorganic nitrogen $(\mathrm{N})$ and phosphorus $(P)$ concentrations typical of aquaculture effluents. Lipidomics analysis, done by hydrophilic interaction liquid chromatography coupled to high resolution mass spectrometry, identified 175 lipid species in the lipid extract of leaves: 140 phospholipids (PLs) and 35 glycolipids (GLs). Plants irrigated with a saline solution with 20-100 mg DIN-N L-1 and 3-15.5 mg DIP-P L-1 under a 1-week hydraulic

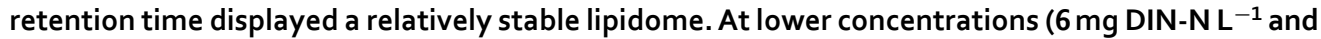
$0.8 \mathrm{mg}$ DIP-P L ${ }^{-1}$ ), plants exhibited less PLs and GLs per unit of leaves dry weight and the GLs fraction of the lipidome changed significantly. This study reveals the importance of analyzing the lipidomic profile of halophytes under different nutritional regimens in order to establish nutrient-limitation thresholds and assure production conditions that deliver a final product with a consistent lipid profile.

Halophyte plants display unique physiological and ecological adaptations to salt-marsh ecosystems, which allow them to live and thrive under a wide range of salt concentrations that most plants are unable to tolerate ${ }^{1-4}$. These plants have been investigated in several contexts, providing important insights on salt-tolerance mechanisms in order to improve salt-sensitive $\mathrm{crops}^{5-7}$. Moreover, their potential as alternative agricultural crops have also been investigated for multiple applications ${ }^{8-12}$. In the context of aquaculture, recent studies have been testing the integration of halophytes production as an approach to extract nutrients from nutrient-rich saline effluents produced by fish-farming activities, which have been recently reviewed by Custódio et al. (2017) ${ }^{13}$. These investigations are typically performed in the context of Integrated Multi-Trophic Aquaculture (IMTA), a conceptual production model regarded as a more sustainable solution for the aquaculture industry ${ }^{14-17}$.

Entrepreneurs and society in general are only recently realizing the potential of halophytes as crops for the future and, besides the more obvious suitability of a handful of species for direct human and animal consumption (e.g. fresh/dried produce, plant meal), a particularly interesting market-positioning strategy for added-value could be the pharmaceutical and nutraceutical industries. Recent studies demonstrated that the leaves from certain halophyte are rich in bioactive molecules, such as phenols, flavonoids and other lipophilic compounds ${ }^{8,18-23}$.

Marine lipids are regarded as an untapped pool of molecules with nutraceutical and pharmaceutical potential, especially those from marine macrophytes ${ }^{10,22,24-27}$. Glycolipids (GLs) and phospholipids (PLs) present in seaweeds (e.g. Codium tomentosum Stackhouse, Gracilaria spp., Porphyra dioica J. Brodie \& L. M. Irvine) displayed antioxidant, anti-inflammatory and antibacterial properties and their fatty acid composition is rich in polyunsaturated aliphatic chains, which increase their functional properties for human health ${ }^{20,21,28-30}$. Several

${ }^{1}$ ECOMARE, Centre for Environmental and Marine Studies (CESAM), Department of Biology, University of Aveiro, Santiago University Campus, 3810-193, Aveiro, Portugal. ${ }^{2}$ ECOMARE, Centre for Environmental and Marine Studies (CESAM), Department of Chemistry, University of Aveiro, Santiago University Campus, 3810-193, Aveiro, Portugal. ${ }^{3}$ Mass Spectrometry Center, Department of Chemistry \& QOPNA \& LAOV - Requinte, University of Aveiro, Campus Universitário de Santiago, 3810-193, Aveiro, Portugal. *email: mfc@ua.pt; rjcalado@ua.pt 
15

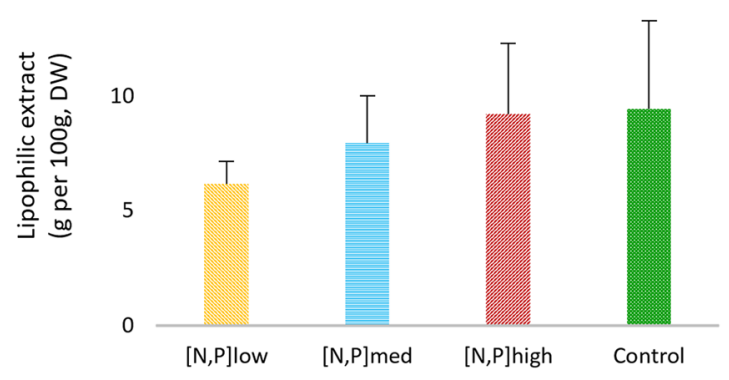

Figure 1. Total amount of the lipid extract of Halimione portulacoides leaves. Error bars represent standard deviations.

bioactive properties have been related to GLs and PLs (e.g. anti-inflammatory and anticarcinogenic) as well as enhanced human cognitive functions and motor performance ${ }^{28,31-36}$. Halophytes, contrarily to algae, have been particularly overlooked on that regard, and the existing lipid characterizations have been mostly limited to fatty acids, non-polar lipids and sterols $s^{19,22,37,38}$. To date, only one publication attempted to describe the polar lipidome of two edible halophyte species (Salicornia ramosissima J. Woods and Halimione portulacoides (L.) Aellen), using liquid-chromatography coupled with mass-spectrometry (LC-MS $)^{22}$. Fully exploring the lipidome of halophytes is a major step towards their valorization as relevant cash-crops for both agriculture and aquaculture. Besides it is also important to take into consideration the potential variations in their lipidomic profile in response to changes in environmental and metabolic conditions ${ }^{10,37,39-41}$. Understanding the circumstances and extent of those variations is essential to guarantee the supply of a consistent product when a stable lipid profile is a requisite.

The present study aimed to describe and assess potential shifts in the lipidome of sea purslane $H$. portulacoides leaves, grown hydroponically under different concentrations of dissolved inorganic nitrogen (DIN) and phosphorous (DIP). The concentrations used in this study aim to represent a wide range of possible values, as recorded in aquaculture effluents used in previous halophyte bioremediation studies under IMTA conditions ${ }^{42-46}$. To understand if contrasting concentrations of DIN and DIP affect the polar lipidome of $H$. portulacoides leaves, the present study tested the following null hypothesis $\left(\mathrm{H}_{0}\right)$ : 'There are no significant changes in the polar lipidome of $H$. portulacoides cultivated in low-, medium- and high-input of DIN and DIP'. Lipid profile was evaluated by state of the art lipidomics analysis using HILIC coupled with mass spectrometry (MS) and tandem mass spectrometry (MS/MS), bioinformatic tools and statistical analysis.

\section{Results}

Total lipids, glycolipids and phospholipids quantification. Total lipid content was estimated by gravimetry and expressed as $g 100 g^{-1}$ of dry weight (DW) (Fig. 1). Non-significant differences were detected between each treatment and the control (CT), with a tendency for increased lipid content in the leaves of $H$. por-

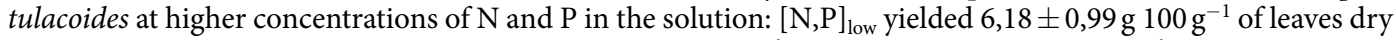

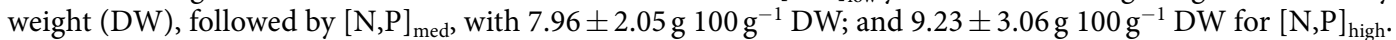
The total amount of lipid extract obtained from $[\mathrm{N}, \mathrm{P}]_{\text {high }}$ was similar to that recorded in the CT $(9.44 \pm 3.83 \mathrm{~g}$ $\left.100 \mathrm{~g}^{-1} \mathrm{DW}\right)$.

The levels of GLs and PLs present in the lipid extracts of the leaves of $H$. portulacoides were also estimated (Fig. 2A), expressed as $\mu g m g^{-1}$ of lipid extract. No significant differences were detected between treatments in neither GLs nor PLs contents. The overall average content of GLs was $455.87 \pm 57.32 \mu \mathrm{g} \mathrm{mg} \mathrm{g}^{-1}$ of lipid extract and that of PLs was $175.49 \pm 39.56 \mu \mathrm{g} \mathrm{mg}^{-1}$ of lipid extract.

Significant differences were recorded between treatment conditions regarding the concentration of GLs and PLs in the leaves of $H$. portulacoides, expressed as $m g g^{-1} \mathrm{DW}$ (Fig. $2 \mathrm{~B}$ ). The $[\mathrm{N}, \mathrm{P}]_{\text {low }}$ group had a significantly lower concentration of GLs $\left(29.1 \mathrm{mg} \mathrm{g}^{-1} \mathrm{DW}\right)$ than the CT $\left(42.1 \mathrm{mg} \mathrm{g}^{-1} \mathrm{DW}\right)$ and other treatments (38.2$\left.39.1 \mathrm{mg} \mathrm{g}^{-1} \mathrm{DW}\right)$, as well as a significantly lower concentration of PLs $\left(9.7 \mathrm{mg} \mathrm{g}^{-1} \mathrm{DW}\right)$ than the CT $\left(17.5 \mathrm{mg} \mathrm{g}^{-1}\right.$ $\mathrm{DW})$ and other treatments $\left(14.1-16.8 \mathrm{mg} \mathrm{g}^{-1} \mathrm{DW}\right)$. The $[\mathrm{N}, \mathrm{P}]_{\text {med }}$ and $[\mathrm{N}, \mathrm{P}]_{\text {high }}$ groups did not differ from the CT in either type of lipids.

Lipidomic signature. A non-targeted lipidomics approach was used to evaluate the stability of the lipidome across treatment conditions. This approach provided a global profile of the polar lipid molecular species present in the extracts and potentially used as a lipid signature that characterizes states of $\mathrm{N}$ and $\mathrm{P}$ limitation and/or excess.

MS and MS/MS analysis allowed the accurate identification of 175 lipid species, namely 140 PLs (Table 1) and 35 GLs (Table 2), which were detected in all conditions. In a few cases, MS/MS spectra did not provide enough information to determine the fatty acyl composition, but the class was confirmed through the identification of the polar head and are therefore included in Table 1. No lipids were found to be unique to any one condition. The lipid classes identified were previously recorded in wild specimens ${ }^{27}$ and are DGDGs, LPCs, LPEs, MGDGs, MGMG, PAs, PCs, PEs, PGs, PIs and SQDGs. The number of species identified per lipid class is represented in Fig. 3.

After raw data processing and species identification, the dataset was analyzed using chemometric statistical methods to extract and interpret data from a biologically relevant perspective, looking at changes in the 
A Lipid extract

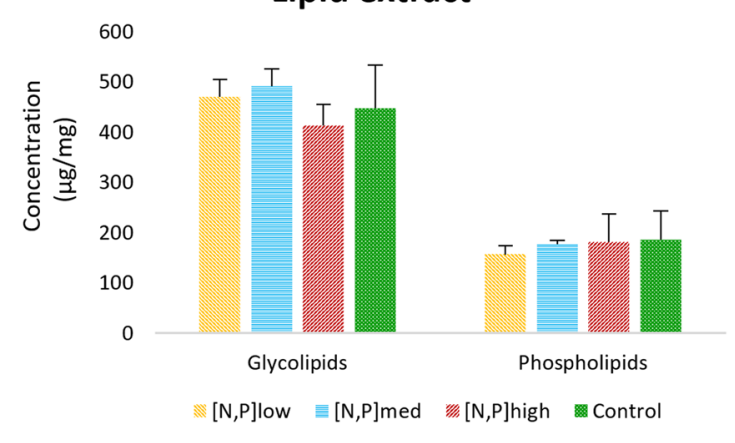

B Leaves

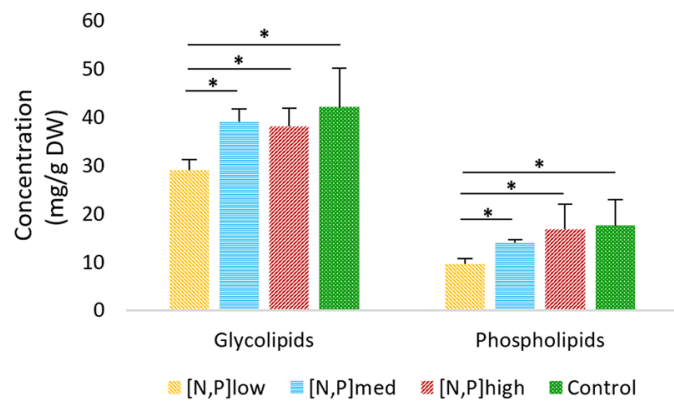

Figure 2. Glycolipids and phospholipids concentrations in (A) leaves lipid extract and in (B) leaves dry mass of Halimione portulacoides. Error bars represent standard deviations and horizontal lines with symbol * represent significant differences: ${ }^{*} \mathrm{p}<0,05 ; * * \mathrm{p}<0,01$.

lipidome in general and within specific lipid groups (GLs and PLs). A PCA analysis was applied to a matrix with all lipid species, to highlight possible changes in the total lipidome imposed by treatments, from which scores plot (Fig. 4A) and loadings plot (supplementary Figure S1-A available as Supplementary Material) of the two principal components were obtained. PCA did not differentiate treatment conditions and there was a higher degree of variability within the CT group (and, to a lesser extent, in $[\mathrm{N}, \mathrm{P}]_{\text {high }}$ ) compared with the other treatments.

Following this observation, PLS-DA was used to maximize the separation between conditions and the projection plot (Fig. $5 \mathrm{~A}$ ) revealed some degree of discrimination between $[\mathrm{N}, \mathrm{P}]_{\text {low }}$ and both $\mathrm{CT}$ and $[\mathrm{N}, \mathrm{P}]_{\text {high }}$. There was no discrimination between $\mathrm{CT}$ and both $[\mathrm{N}, \mathrm{P}]_{\text {med }}$ and $[\mathrm{N}, \mathrm{P}]_{\text {high }}$. The Variable Importance in Projection (VIP) scores were used to rank variables in terms of their importance in the projection of the PLS model, and the top 20 variables are presented in Fig. 5D. Fifteen out of those twenty species presented higher concentrations in $[\mathrm{N}, \mathrm{P}]_{\text {low }}$ than $\mathrm{CT}$ and $[\mathrm{N}, \mathrm{P}]_{\text {high. }}$. Nonetheless, within the top five species explaining the separation, three were at lowest concentrations (PA 34:1, PA 36:3, PA 34:2) and two at highest concentrations (PI 36:6, DGDG 34:3) in [N,P] $]_{\text {low. }}$

PCA and PLS-DA were also applied to matrices composed of only PL or GL molecular species, in order to decipher if any one of these two major lipid groups were changing more markedly than the other. The PCA of PLs (Fig. 4B; loadings in supplementary Figure S1-B) showed a very similar trend to the PCA plotted for the total lipidome data, suggesting no clear discrimination between treatment conditions. Similarly, the PLS-DA (Fig. 5B) also resembles the one obtained with the total lipidome matrix, with the most important species influencing the model also being PA 34:1, PA 36:3, PA 34:2 and PI 36:6 (Fig. 5E).

The PCA of GLs (Fig. 4C; loadings in supplementary Figure S1-C), on the other hand, evidences a clear separation between the $[\mathrm{N}, \mathrm{P}]_{\text {low }}$ group and both $\mathrm{CT}$ and $[\mathrm{N}, \mathrm{P}]_{\text {high }}$ groups. The PLS-DA model projection (Fig. $5 \mathrm{C}$ ) further discriminates those groups, meanwhile the $[\mathrm{N}, \mathrm{P}]_{\text {med }}$ group intersects both low-input and high-input clusters. The species that most contributes to the separation is DGDG 34:3, followed by MGDG 34:3, SQDG 34:3 and DGDG 36:3, all of them at higher concentrations in $[\mathrm{N}, \mathrm{P}]_{\text {low }}$ than $\mathrm{CT}$ and $[\mathrm{N}, \mathrm{P}]_{\text {high }}$ (Fig. 5F). From the top fifteen GL species influencing the PLS-DA model, fourteen were at highest concentration in $[\mathrm{N}, \mathrm{P}]_{\text {low }}$.

The univariate analysis of individual lipid species intensities (supplementary Figure S2) displayed significant differences between certain treatment groups for PA 34:1, DGDG 34:3, DGDG 36:3 and PI 36:6, all of which were at the top of the VIP scores. MS/MS spectra from all conditions for some of the top VIP features can be consulted in the supplementary Figure S3.

Polar lipid changes in each class. A univariate analysis was also performed regarding the average relative abundance of molecular species within each class of PLs and GLs. In the case of PLs, most of the significant differences in species relative abundance were observed between $[\mathrm{N}, \mathrm{P}]_{\text {low }}$ and either $\mathrm{CT}$ or $[\mathrm{N}, \mathrm{P}]_{\text {high }}$ or both conditions. These were observed in PCs (8 species), PEs (2), PGs (8), PIs (5), LPCs (2) and LPEs (2) (supplementary Figure S4). In PAs, 5 species were significantly different in terms of relative abundance between CT and the other 


\begin{tabular}{|c|c|c|c|}
\hline$[\mathbf{M}+\mathbf{H}]^{+}$ & Lysophosphatidylcholine & 844.6785 & PC 18:1/22:0 \\
\hline 496.3396 & LPC 16:0 & 868.6785 & PC 18:3/24:0; PC 18:2/24:1 \\
\hline 518.3230 & LPC $18: 3$ & 870.6933 & PC 18:2/24:0; PC 18:1/24:1 \\
\hline 520.3387 & LPC 18:2 & & \\
\hline 522.3564 & LPC 18:1 & {$[\mathrm{M}-\mathrm{H}]^{-}$} & Phosphatidylethanolamine \\
\hline 550.3869 & LPC 20:1 & 684.4609 & PE 16:0/16:3; PE 14:0/18:3 \\
\hline 552.4024 & LPC 20:0 & 686.4753 & PE 16:0/16:2; PE 14:0/18:2 \\
\hline 580.4350 & LPC 22:0 & 688.4914 & PE 16:0/16:1; PE 14:0/18:1 \\
\hline \multirow[t]{2}{*}{608.4656} & LPC 24:0 & 708.4596 & PE 16:2/18:3; PE 16:3/18:2 \\
\hline & & 710.4754 & PE 16:1/18:3; PE 16:2/18:2 \\
\hline$[\mathrm{M}-\mathrm{H}]^{-}$ & Lysohosphatidylethanolamine & 712.4916 & PE 16:0/18:3; PE 16:1/18:2 \\
\hline 452.2779 & LPE 16:0 & 714.5068 & PE 16:0/18:2; PE 16:1/18:1 \\
\hline 474.2621 & LPE 18:3 & 716.522 & PE 16:0/18:1 \\
\hline 476.2779 & LPE 18:2 & 734.4766 & PE 18:3/18:3 \\
\hline \multirow[t]{2}{*}{478.2938} & LPE 18:1 & 736.4921 & PE 18:2/18:3 \\
\hline & & \begin{tabular}{|l}
738.5086 \\
\end{tabular} & PE 18:2/18:2; PE 18:1/18:3 \\
\hline$[\mathrm{M}-\mathrm{H}]^{-}$ & Phosphatidic acid & 740.5227 & PE 18:1/18:2 \\
\hline 667.4347 & PA 34:4* & \begin{tabular}{|l|l|}
742.5387 \\
\end{tabular} & PE 18:1/18:1 \\
\hline 669.4505 & PA 16:0/18:3 & 764.5219 & PE 18:0/20:5 \\
\hline 671.4647 & PA 16:0/18:2 & \begin{tabular}{|l|l|}
766.5389 \\
\end{tabular} & PE 18:3/20:1; PE 18:2/20:2 \\
\hline 673.4816 & PA 16:0/18:1 & 768.5536 & PE 18:2/20:1; PE 18:3/20:0; PE 18:1/20:2 \\
\hline 691.4335 & PA 18:3/18:3 & 770.5684 & PE 18:1/20:1; PE 18:2/20:0 \\
\hline 693.4498 & PA 18:2/18:3 & 794.5699 & PE 18:/22:1 \\
\hline 695.4647 & PA 18:2/18:2; PA 18:1/18:3 & 796.5857 & PE 18:3/22:0; PE 18:2/22:1 \\
\hline 697.4812 & PA 18:1/18:2 & 798.5998 & PE 18:2/22:0 \\
\hline \multirow[t]{2}{*}{699.4955} & PA 18:1/18:1 & 800.6154 & PE 18:1/22:0 \\
\hline & & 824.6159 & PE 18:2/24:1; PE 18:3/24:0 \\
\hline$[\mathbf{M}+\mathbf{H}]^{+}$ & Phosphatidylcholine & 826.6316 & PE 18:2/24:0 \\
\hline 700.4889 & PC 30:3* & & \\
\hline 728.5230 & PC 16:0/16:3 & {$[\mathrm{M}-\mathrm{H}]^{-}$} & Phosphatidylglycerol \\
\hline 730.5378 & PC 16:0/16:2; PC 14:0/18:2 & 693.4703 & PG 14:0/16:0 \\
\hline 734.5684 & PC 16:0/16:0 & 719.486 & PG 16:0/16:1; PG 14:0/18:1 \\
\hline 750.5072 & PC 18:3/18:3 & 721.5013 & PG 16:0/16:0; PG 14:0/18:0 \\
\hline 754.5373 & $\begin{array}{l}\text { PC 16:1/18:3; PC 16:2/18:2; PC } \\
\text { 16:3/18:1 }\end{array}$ & 739.4554 & PG 16:1/18:4; PG 16:2/18:3; PG 16:3/18:2 \\
\hline 756.5538 & PC 16:0/18:3; PC 16:1/18:2 & 741.4701 & $\begin{array}{l}\text { PG 16:0/18:4; PG 16:1/18:3; PG 16:2/18:2; PG } \\
\text { 16:3/18:1 }\end{array}$ \\
\hline 758.5690 & PC 16:0/18:2; PC 16:1/18:1 & 743.4861 & PG 16:0/18:3; PG 16:1/18:2; PG 16:2/18:1 \\
\hline 760.5829 & PC 16:0/18:1 & 745.5014 & PG 16:1/18:1; PG 16:2/18:0; PG 16:0/18:2 \\
\hline 772.4896 & PC 36:9* & 747.5162 & PG 16:0/18:1; PG 16:1/18:0 \\
\hline 776.5193 & PC $36: 7^{*}$ & 763.4543 & PG 18:3/18:4 \\
\hline 778.5370 & PC 18:3/18:3 & 765.4716 & PG 18:3/18:3; PG 18:2/18:4 \\
\hline 780.5529 & PC 18:2/18:3 & 767.4850 & PG 18:2/18:3 \\
\hline 782.5682 & PC 18:2/18:2; PC 18:1/18:3 & 769.5012 & PG 18:2/18:2; PG 18:1/18:3; PG 16:1/20:3 \\
\hline 784.5841 & PC 18:1/18:2; PC 18:0/18:3 & 771.5160 & PG 18:1/18:2 \\
\hline 786.5997 & PC 18:1/18:1; PC 18:0/18:2 & 773.5316 & PG 18:1/18:1; PG 18:0/18:2; PG 16:0/20:2 \\
\hline 800.5198 & PC 38:9* & 775.5458 & PG 16:0/20:1; PG18:0/18:1 \\
\hline 802.5347 & PC $38: 8^{*}$ & & \\
\hline 804.5510 & PC $38.7^{*}$ & {$[\mathrm{M}-\mathrm{H}]^{-}$} & Phosphatidylinositol \\
\hline 806.5667 & PC 38:6* & 831.5016 & PI 16:0/18:3 \\
\hline 808.5818 & PC 18:2/20:3; PC 18:3/20:2 & 833.5165 & PI 16:0/18:2 \\
\hline 810.5978 & PC 18:3/20:1; PC 18:2/20:2 & 835.5318 & PI 16:0/18:1 \\
\hline 812.6158 & PC 18:2/20:1 & 853.4849 & PI 18:3/18:3 \\
\hline 814.6334 & PC 18:1/20:1; PC 18:2/20:0 & 855.5002 & PI 18:2/18:3 \\
\hline 832.5815 & PC 40:7* & 857.5163 & PI 18:2/18:2; PI 18:1/18:3 \\
\hline 834.5967 & PC 40:6* & 859.5319 & PI 18:1/18:2 \\
\hline 838.6321 & PC 18:3/22:1 & 861.5471 & PI 18:1/18:1; PI 18:0/18:2 \\
\hline 840.6473 & PC 18:3/22:0; PC 18:2/22:1 & 863.5607 & PI 18:1/18:0 \\
\hline 842.6634 & PC 18:2/22:0; PC 18:1/22:1 & & \\
\hline
\end{tabular}

Table 1. Phospholipids molecular species identified by LC-MS and tandem MS (MS/MS) from total lipid extracts of Halimione portulacoides leaves. ${ }^{*}$ confirmed $m / z$ and class but missing fatty-acyl information to identify species. 


\begin{tabular}{|l|l|l|l|}
\hline$\left[\mathbf{M}+\mathbf{N H}_{4}\right]^{+}$ & Digalactosyldiacylglycerol & {$\left[\mathbf{M}+\mathbf{N H}_{4}\right]^{+}$} & Monogalactosylmonoacylglycerol \\
\hline 910.6472 & DGDG 16:0/16:0 & 532.3482 & MGMG 18:3 \\
\hline 926.5816 & DGDG 18:3/16:3 & & \\
\hline 932.6296 & DGDG 18:3/16:0; DGDG 18:2/16:1 & {$[\mathbf{M}-\mathbf{H}]^{-}$} & Sulfoquinovosyldiacylglycerol \\
\hline 936.6576 & DGDG 18:1/16:0 & 787.4660 & SQDG 18:3/14:0; SQDG 16:3/16:0 \\
\hline 954.6144 & DGDG 18:3/18:3; DGDG 18:4/18:2 & 789.4800 & SQDG 18:2/14:0 \\
\hline 958.6440 & DGDG 18:3/18:1; DGDG 18:2/18:2 & 791.4970 & SQDG 16:1/16:0 \\
\hline 960.6601 & DGDG 18:3/18:0; DGDG 18:2/18:1 & 793.5120 & SQDG 16:0/16:0 \\
\hline & & 813.4820 & SQDG 18:3/16:1 \\
\hline$\left[\mathbf{M}+\mathbf{N H}_{4}\right]^{+}$ & Monogalactosyldiacylglycerol & 815.4970 & SQDG 18:3/16:0 \\
\hline 764.5308 & MGDG 18:3/16:3; MGDG 18:4/16:2; & 837.4800 & SQDG 18:3/18:3 \\
\hline 768.5630 & MGDG 18:2/16:4 & 839.4970 & SQDG 18:3/18:2; SQDG 20:2/16:3 \\
\hline 770.5768 & MGDG 18:3/16:0; MGDG 18:2/16:1; & 843.5280 & SQDG 18:3/18:0; SQDG 18:2/18:1 \\
\hline 792.5615 & MGDG 18:0/16:3 & & \\
\hline 796.5910 & MGDG 18:2/18:2; MGDG 18:3/18:1 & & \\
\hline
\end{tabular}

Table 2. Glycolipids molecular species identified by LC-MS and tandem MS (MS/MS) from total lipid extracts of Halimione portulacoides leaves.

A

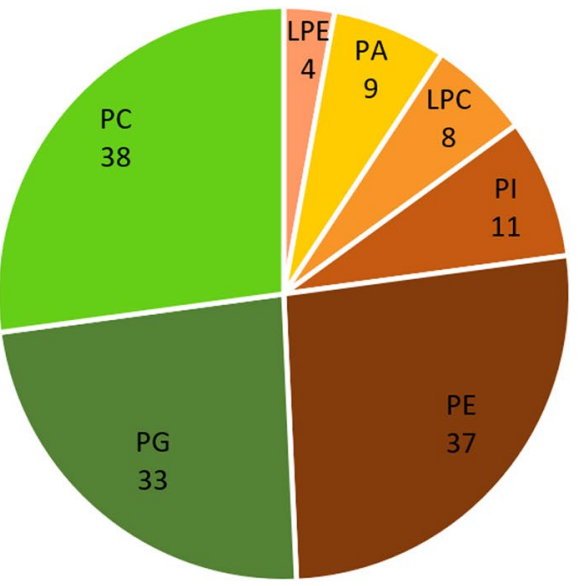

B

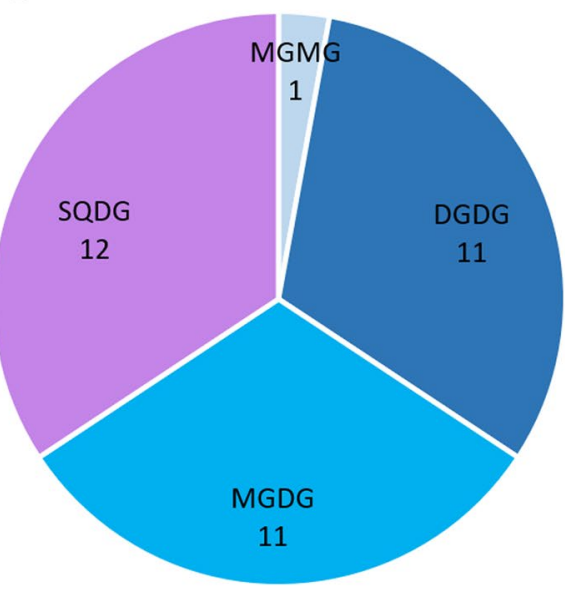

Figure 3. Number of (A) phospholipids and (B) glycolipids molecular species identified in the lipid extract of Halimione portulacoides leaves by MS/MS. DGDG - digalactosyldiacylglycerol; LPC lysophosphatidylcholine; LPE - lysophosphatidylethanolamine; MGDG - monogalactosyldiacylglycerol; MGMG - monogalactosylmonoacylglycerol; PA - phosphatidic acid; PC - phosphatidylcholine; PG - phosphatidylglycerol; PE - phosphatidylethanolamine; PI - phosphatidylinositol; SQDG sulfoquinovosyldiacylglycerol.

treatments. In the case of GLs, differences were mostly observed between $[\mathrm{N}, \mathrm{P}]_{\text {low }}$ and either CT or $[\mathrm{N}, \mathrm{P}]_{\text {high }}$ or both, in DGDGs (4 species), MGDGs (4) and SQDGs (5) (supplementary Figure S5).

Some lipid species with similar fatty acyl chains were more abundant in $[\mathrm{N}, \mathrm{P}]_{\text {low }}$, such as $\mathrm{PC}, \mathrm{PE}, \mathrm{PG}, \mathrm{PI}$, DGDG and SQDG with 34 carbons and 3 double bonds (34:3) and the PC, PE, PA and DGDG with 36 carbons and 6 double bonds (36:6). Regarding lyso-forms, the LPC 18:3 and LPE 18:3 were also more abundant in $[\mathrm{N}, \mathrm{P}]_{\text {low }}$. The lipid species that were lower in $[\mathrm{N}, \mathrm{P}]_{\text {low }}$ when compared with CT were more diversified in their fatty acyl composition and included several PLs (e.g. PC and PA 36:3, PC 32:2, PA 34:2, PI and PG 32:1), two lyso-PLs (LPC and LPE 16:0) and some GLs (e.g. MGDG 34:6, DGDG 34:6 and, SQDG 34:4). Other differences were observed between the $[\mathrm{N}, \mathrm{P}]_{\text {low }}$ and $[\mathrm{N}, \mathrm{P}]_{\text {high }}$ conditions: $[\mathrm{N}, \mathrm{P}]_{\text {low }}$ treatment resulted in significantly lower relative abundance of PG 32:1 and 34:4, PI 34:2, SQDG 32:0, 32:1, 32:2 and 34:4, MGDG 34:3, 34:4, 36:4, DGDG 34:6 and 36:6; and higher relative abundance of PG 34:2, PI 34:1, SQDG 34:3, DGDG 34:3, 34:6 and 36:3.

\section{Discussion}

The present study evaluated the polar lipidome signature of leaves from hydroponically grown $H$. portulacoides under different concentrations of $\mathrm{N}$ and $\mathrm{P}$. The aim was to describe and reveal possible shifts in the lipidomic profile of its leaves under a wide range of DIN and DIP concentrations that represent possible IMTA contexts. 
PCA - Total lipidome

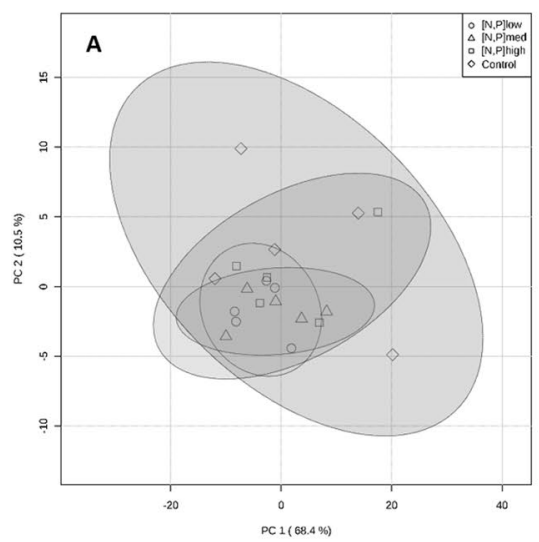

PCA - Phospholipids

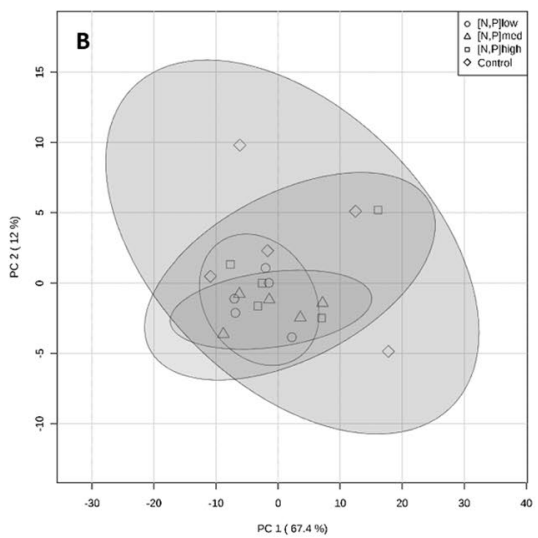

PCA - Glycolipids

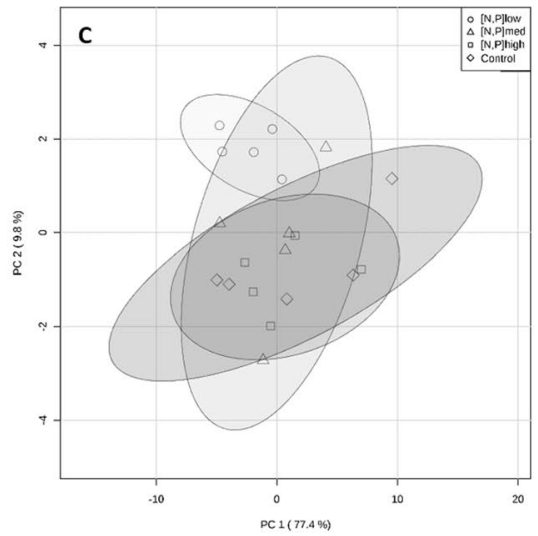

Figure 4. Principal component analysis (PCA) scores plot of (A) total lipidome, (B) phospholipids and (C) glycolipids normalized peak-intensity, obtained from the lipid extracts from Halimione portulacoides leaves.

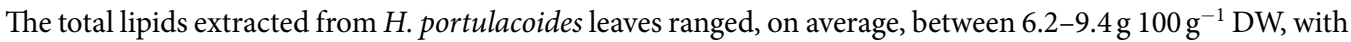
higher amounts extracted from the high-input treatments, including CT (Hoagland's solution). A recent study by Patel et al. (2019) ${ }^{47}$ analyzed the total lipid content in the shoots (which can include leaves and other superior organs) of several halophytes and concluded that non-succulent halophytes (e.g. Sporobolus virginicus (L.) Kunth and Aeluropus lagopoides (L.) Trin. ex Thwaites) presented higher lipid content, between 5.5-7.2 g $100 \mathrm{~g}^{-1} \mathrm{fresh}$ weight (FW), followed by shrubby halophytes (e.g. Atriplex nummularia Lindl. and Atriplex griffithii Moq.) with 2.6-2.8 g $100 \mathrm{~g}^{-1} \mathrm{FW}$, and succulents (e.g. Sesuvium portulacastrum (L.) L. and Salicornia brachiate Miq.), with

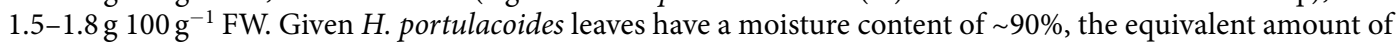

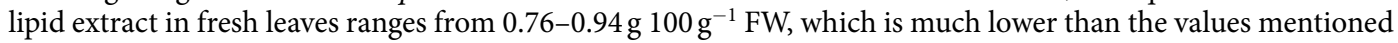
above for other species. Nonetheless, other studies reported values (both in DW and FW) within the same order of magnitude as $H$. portulacoides, which contradict the values reported above. For instance, Salicornia bigelovii

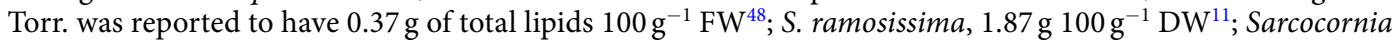

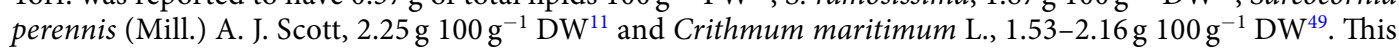
discrepancy could be explained by the inclusion of seeds along with the shoots in Patel et al. (2019), which would substantially increase total lipid content. Yet, total lipids in fertile shoot segments containing seeds were described

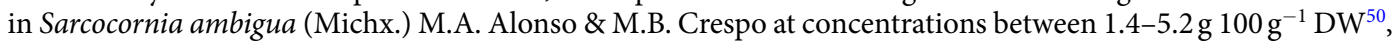

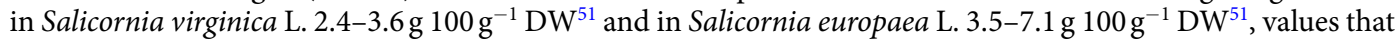
do not match up with the aforementioned concentrations reported for succulents. A misreport of DW as FW could also be a possible explanation for that inconsistency.

PLs and GLs are two major lipid groups present in the total lipid extracts of halophyte leaves, carrying a wide array of fatty acids (FAs), from which $\alpha$-linolenic acid (C18:3, $n-3)$, palmitic acid (C16:0), linoleic acid (C18:2, $n-6)$ and oleic acid $(\mathrm{C} 18: 1, n-9)$ are the most abundant ${ }^{22,52,53}$. In this study, H. portulacoides displayed a profusion of lipid species with $\mathrm{C} 16$ and $\mathrm{C} 18$ chains and some species exhibited polyunsaturated fatty acids with up to four double-bonds (e.g. MGDG 18:2/16:4; PG 16:0/18:4 and PG 18:2/18:4). Polyunsaturated FAs have been largely associated with beneficial health effects in humans and animals ${ }^{54-58}$ and $H$. portulacoides leaves can be a good source for obtaining those FAs, given its relatively high lipid content compared with other halophytes.

The quantities of GLs and PLs in the lipid extract were comparable across treatments. The GLs constituted approximately $46 \%$ of the total extract, PLs constituted around $18 \%$ and, therefore, polar lipids constituted $64 \%$ of the total. When the concentrations were expressed in relation to the dry weight (DW) of leaves, GLs and PLs turned out to be significantly lower in $[\mathrm{N}, \mathrm{P}]_{\text {low }}$ treatment. Higher percentages of polar lipids were previously observed in other halophytes, especially GLs. For instance, the total lipidic extract of chloroplast-enriched portions from Salicornia perennans Willd. was reported to have 67\% GLs and 31\% PLs; Limonium gmelinii (Willd.) Kuntze, 60\% GLs and 32\% PLs; and Artemisia santonicum L., 80\% GLs and 15\% PLs ${ }^{59}$. Other halophytes displayed lower percentages of GLs, such as Halostachys caspica C.A.Mey. and Halocharis hispida (Schrenk) Bunge, with 22-29\% GLs and 16-17\% PLs in their extract ${ }^{60}$. In terms of the amounts of GLs and PLs per unit of leaves, a previous study reported values for several halophyte species to range between 5-47 mg GLs g ${ }^{-1} \mathrm{DW}$ and 2-17 mg PLs $\mathrm{g}^{-1} \mathrm{DW}^{61}$. Concerning the present study, $H$. portulacoides from the high-input treatments displayed values very similar to the upper-end of those ranges. Nonetheless, comparisons should be taken merely as an illustration of the range of possible concentrations in the edible portions of different species of halophytes.

Regarding the lipidome, the null hypothesis under test stated that no changes occur in the polar lipidome of H. portulacoides cultivated in low-, medium-and high-input of DIN and DIP. Since P is an important element of polar lipids, hydroponic conditions that would offer limited access of this element to the plant could promote alterations in the lipidome of leaves. A decrease in PLs in parallel with an increase in non-phosphorus GLs (e.g. SQDG and DGDG) and betaine lipids (in algae) was observed in plants and algae when exposed to conditions of P-limitation, as previously reported for Arabidopsis ${ }^{62-65}$, rice $^{66}$, oat ${ }^{67}$, soybean ${ }^{66,68}$, periphyton ${ }^{69}$ and $U l v a^{70}$. From the PCA results it follows that the total lipidome signature of $H$. portulacoides leaves remained relatively 

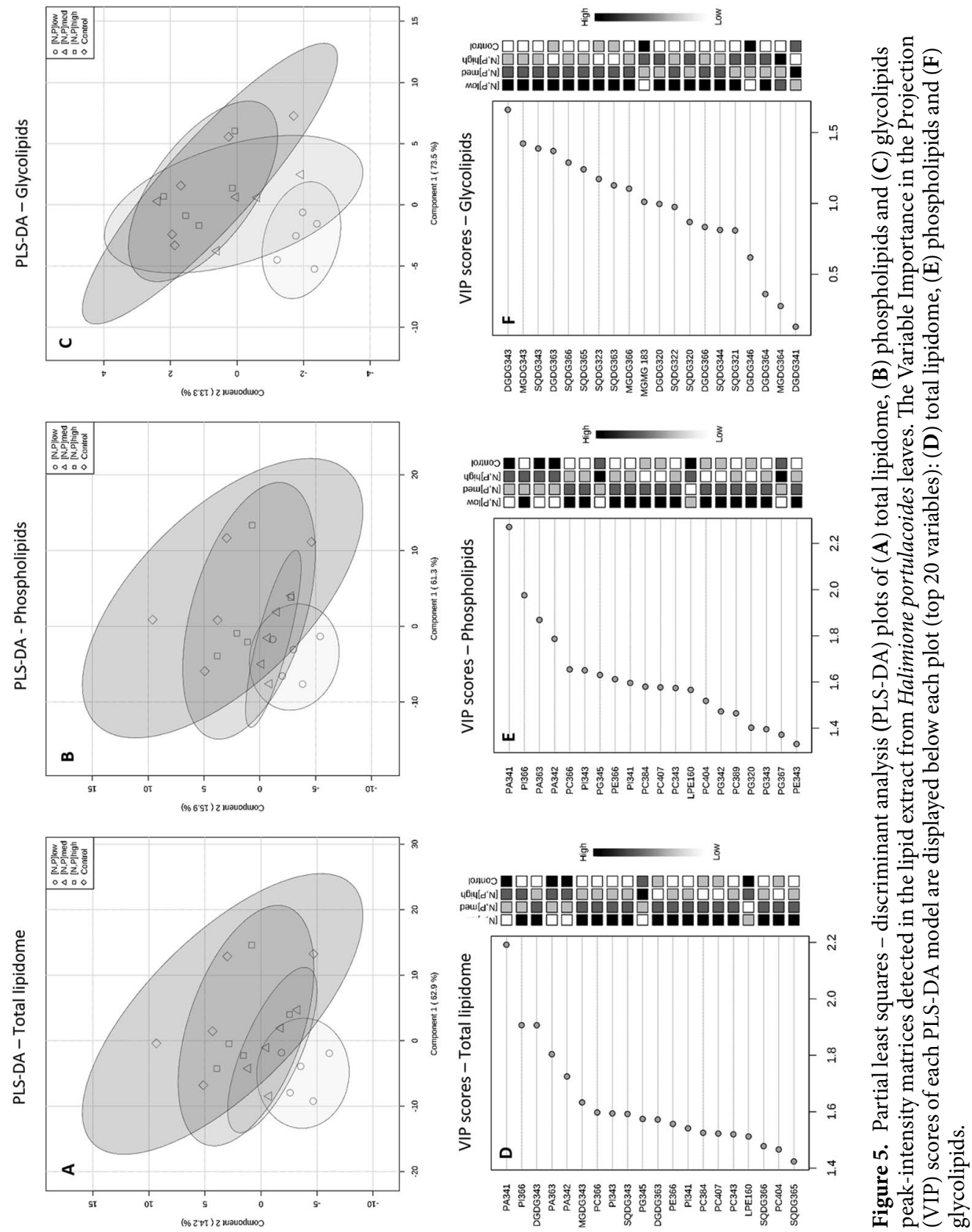

unchanged across groups after long-term exposure to nutrient concentrations varying between 6-100 mg DIN-N $\mathrm{L}^{-1}$ and $0.8-15.5 \mathrm{mg}$ DIP-P L $\mathrm{L}^{-1}$. However, a sequential overlap of treatment groups, from lowest to highest P-input $\left([\mathrm{N}, \mathrm{P}]_{\text {low }}<[\mathrm{N}, \mathrm{P}]_{\text {med }}<[\mathrm{N}, \mathrm{P}]_{\text {high }}<\mathrm{CT}\right)$, was evident in the PLS-DA projection. The $[\mathrm{N}, \mathrm{P}]_{\text {low }}$ group stood out as the group with the least amount of overlap with the other groups. When GLs were analyzed separately from PLs, both PCA and PLS-DA plots evidently discriminated the $[\mathrm{N}, \mathrm{P}]_{\text {low }}$ group from both the $\mathrm{CT}$ and $[\mathrm{N}, \mathrm{P}]_{\text {high }}$ groups. These results suggest that the GL profile of the leaves is changing according to the availability of $\mathrm{P}$, but its effect on the total polar lipidome is masked by the PL profile which remains relatively stable across treatments. Therefore, at low-input concentrations of $\mathrm{P}$, the leaves of $\mathrm{H}$. portulacoides display a low degree of lipidome remodulation associated with significant changes in GLs. In plants, GLs are typically found in chloroplast thylakoids, being their major lipid constituents, but under P-limited conditions, GLs (particularly DGDG) can partially replace PLs in extra-plastidial membranes ${ }^{71}$. The upregulation of genes encoding GLs synthase (ex. DGD1, DGD2, MGD2/ MGD3) which activate additional GLs biosynthetic pathways in plants under P-limited conditions ${ }^{71-73}$ could explain the changes observed in H. portulacoides' GL profile under the conditions of low P-input. Previous studies, in both plants and microalgae, demonstrated that the availability of $\mathrm{N}$ also affects the morphology and function of chloroplasts in superior plants and microalgae ${ }^{74-78}$ and an accumulation of GLs can be therefore observed under both $\mathrm{N}$ - and P-limitation. The GL species that most contributed to the discrimination of treatment groups in the PLS-DA models (i.e. MGDG 34:3, DGDG 34:3, SQDG 34:3, DGDG 36:3 and SQDG 36:6) also displayed a significantly higher relative abundance in $[\mathrm{N}, \mathrm{P}]_{\text {low }}$ than in either $\mathrm{CT}$ or $[\mathrm{N}, \mathrm{P}]_{\text {high }}$. 
The PLs that allowed some discrimination between groups were PA 34:1, PA 36:3 PA 34:2, PI 36:6 and PC 36:6. The PAs displayed higher intensity as the input of P increased meanwhile PI 36:6 and PC 36:6 displayed an opposite pattern. This is also evident from PAs relative abundances, as PA 34:1, PA 34:2 and PA 36:3 were more abundant in CT than the other groups, meanwhile C36:6 species were generally in lower abundance in CT. In plants, PAs are precursors of PL and GL synthesis and also function as signal molecules of environmental stress ${ }^{79}$. The marked differences in abundance of several PA species between CT and the other treatments could be related to the activation of different metabolic pathways mediated by the availability of P. Moreover, certain FA configurations were constantly associated with lipid species that displayed significant differences in relative abundance (e.g. C34:1, C34:2, C34:3 and C36:6). For instance, C34:3 displayed the highest abundance in $[\mathrm{N}, \mathrm{P}]_{\text {low }}$ across all classes of PLs (except PA) and GLs. In general, variations in relative abundance were observed most evidently between $[\mathrm{N}, \mathrm{P}]_{\text {low }}$ and both the $\mathrm{CT}$ and $[\mathrm{N}, \mathrm{P}]_{\text {high }}$ treatments, suggesting a possible metabolic adaptation from high-input to low-input conditions.

Following the observations discussed above, $H$. portulacoides was probably under some level of nutrient limitation under $[\mathrm{N}, \mathrm{P}]_{\text {low. }}$. Firstly, they exhibited less PLs and GLs per unit weight of leaves. Secondly, GLs were suffering some degree of remodulation. Thirdly, the relative abundances of certain species in each class changed as a function of $\mathrm{N}$ and/or $\mathrm{P}$ availability, as suggested by their gradual increase (or decrease) from low-input to high-input of $\mathrm{N}$ and/or P. Nonetheless, one could argue about the extent of nutrient limitation that $H$. portulacoides was potentially exposed to under the $[\mathrm{N}, \mathrm{P}]_{\text {low }}$ treatment, by looking at how other plants behaved in similar conditions. For instance, wild specimens of Arabidopsis thaliana (L.) Heynh, exposed to $0.03 \mathrm{mMP}$ (similar to $[\mathrm{N}, \mathrm{P}]_{\text {low }}$ ) during 12 days followed by 4 days without $\mathrm{P}$, were considered P-starved as they clearly exhibited significant decreases in shoot's PLs (PC, PE, PG and PS) and significant increases in shoot's GLs (MGDG, DGDG, SQDG $)^{80}$. Some species of MGDG and DGDG were also found at markedly higher levels in soybean (Glycine max (L.) Merr.) leaves under P-limited conditions ${ }^{68}$. In this experiment, $H$. portulacoides did not exhibit such patent changes in the lipidome in the low-input conditions, which indicates that plants were not starved. Note, however, that $H$. portulacoides is a perennial plant and both A. thaliana and G. max are annual plants, and these different life history strategies might affect nutrient utilization and threshold conditions for nutrient-limitation ${ }^{81,82}$. Another important fact to consider is that the impact of P-limitation might not affect leaves homogeneously. For instance, in G. max under P-limitation, there seems to be a mechanism of P-remobilization from older leaves, where differences in the lipidome between limited and non-limited conditions were substantial, to younger leaves, where the lipidome profile between different conditions were very similar ${ }^{68}$. In the present study there was no control regarding leaves' age, as the lipidome was representative of the total pool of leaves from $H$. portulacoides.

Plants in general display a range of responses to low $\mathrm{P}$, generally referred to as P-starvation responses, that aim to minimize the negative effects of its scarcity in plants (e.g. decreased growth, increased root/shoot ratio, increased root-hair density, increased carboxylate exudation, P-remobilization) ${ }^{83-87}$. Under the conditions of the present experiment, the extent to which $H$. portulacoides underwent a starvation response under $[\mathrm{N}, \mathrm{P}]_{\text {low }}$ that affected the polar lipids of its leaves was defined by a decrease in total GLs and PLs and some degree of lipid remodulation detected in the GLs pool. The availability of $\mathrm{P}$ was still high enough in the low-input treatment to maintain the PLs pool relatively unchanged.

Within an IMTA framework, it is fair to conclude that $H$. portulacoides is capable of maintaining a fully stable lipidome across a variety of $\mathrm{N}$ and $\mathrm{P}$ concentrations typical of aquaculture effluents, specifically $20-100 \mathrm{mg}$ DIN-N L ${ }^{-1}$ and 3-15.5 mg DIP-P L ${ }^{-1}$. At lower concentrations (e.g. [N,P] low values: $6 \mathrm{mg} \mathrm{DIN}-\mathrm{N} \mathrm{L}{ }^{-1}$ and $0.8 \mathrm{mg}$ DIP-P $\mathrm{L}^{-1}$ ) the lipidome of the leaves displays some changes, particularly regarding GLs, as well as generalized decrease in the quantity of polar lipids in the leaves. These changes suggest a metabolic adaptation to the lower nutrient conditions and could be indicative of nutrient limitation. Data on growth performance supports a scenario of nutrient-limited conditions in $[\mathrm{N}, \mathrm{P}]_{\text {low }}$, as $\mathrm{H}$. portulacoides exposed to those same concentration of $\mathrm{N}$ and $\mathrm{P}$ produced less biomass than those exposed to higher concentrations (Custódio et al., unpublished data).

Halimione portulacoides appears to be a good candidate for IMTA in terms productivity and nutrient-extraction ${ }^{44,88}$ and has the potential to become a valuable co-product with uses in human nutrition ${ }^{11}$ and for other applications ${ }^{13,22,30}$. A note should be made, however, about the possibility of halophytes accumulating undesired compounds if these are present in effluents, like metals ${ }^{89,90}$ and chemicals used for therapy and prophylaxis in aquaculture ${ }^{91}$. This possibility must be taken into account when selecting halophytes for IMTA, since the accumulation of contaminants in edible plant organs can pose risks to human health ${ }^{92}$ and species that do not accumulate or concentrate contaminants mostly in non-edible tissues will be more appropriate from a product-safety perspective. The same concern has been put forward regarding other extractive species (e.g. seaweeds) and changes in regulatory frameworks are necessary to promote safety of new products from IMTA ${ }^{93,94}$.

Determining which nutritional conditions can lead to nutrient-limitation scenarios is important information for future IMTA/halophyte producers, in order to guide nutrition strategies that guarantee a consistent end-product, especially under highly variable nutritional outputs which can occur in aquaculture activities. For researchers, this data can guide the establishment of reference nutritional concentrations for future studies targeting the production of $H$. portulacoides. Future lipidomic studies in $H$. portulacoides should also attempt to characterize and quantify seed oils, since these comprise a significant fraction of the aboveground biomass during the reproductive period of this species and could have valuable high-end applications, such as pharmaceuticals, biofuels, detergents, polymers and cosmetics.

Fully characterizing the diversity of lipid species across $H$. portulacoides tissues and how they change along the production cycle and environmental conditions is of tremendous importance for the commercial exploration of its lipids. This will allow for strategic choices to be made on how to produce it and manipulate its life cycle so to maximize the delivery of value-added compounds with commercial applications and consequently increase its economic value. 


\section{Material and Methods}

Plant material. Halimione portulacoides stems were harvested on April 2017 at Ria de Aveiro (mainland Portugal) $\left(40^{\circ} 38^{\prime} 04.1^{\prime \prime} \mathrm{N} 8^{\circ} 39^{\prime} 40.0^{\prime \prime} \mathrm{W}\right)$ and 500 grafts with 4 nodes each were cut, put into polyethylene containers, irrigated with a modified Hoagland's solution and placed under natural sunlight and temperature to promote root development. The elemental composition of the modified Hoagland's solution was: $60 \mathrm{mg} \mathrm{K} \mathrm{L}^{-1}, 56 \mathrm{mg} \mathrm{N} \mathrm{L}^{-1}$, $40 \mathrm{mg} \mathrm{Ca} \mathrm{L}^{-1}, 16 \mathrm{mg} \mathrm{Mg} \mathrm{L}^{-1}, 16 \mathrm{mg} \mathrm{P} \mathrm{L}{ }^{-1}, 1.12 \mathrm{mg}$ Fe L-1, $0.34 \mathrm{mg} \mathrm{Mo} \mathrm{L-1,} 0.28 \mathrm{mg} \mathrm{B} \mathrm{L}^{-1}, 0.13 \mathrm{mg} \mathrm{Zn} \mathrm{L}^{-1}, 0.11 \mathrm{mg}$ $\mathrm{Mn} \mathrm{L}^{-1}$ and $0.03 \mathrm{mg} \mathrm{Cu} \mathrm{L}^{-1}$. After three months, in July 2017, rooted plants were transferred and acclimated to indoor conditions for two weeks. In the second week, plants were progressively exposed to a target water salinity of $20 \mathrm{ppt}$, with increments of 5 every second day, prior to the beginning of the experiment.

Growth trial. The hydroponics growth trial took place indoors at ECOMARE (Laboratory for Innovation and Sustainability of Marine Biological Resources of University of Aveiro) facilities, during 10 weeks (from July to September under an artificial photoperiod of 14 light: 10 dark) to allow plants to develop a harvestable aboveground biomass. The hydroponic units were made of opaque polypropylene material, with dimensions of $300 \times 200 \times 170 \mathrm{~mm}$ and a volume of $5 \mathrm{~L}$ of solution maintained through an overflow outlet. Twenty polystyrene floating-rafts were perforated with ten holes equally spaced between them $(20 \mathrm{~mm})$ and 200 three-months old rooted grafts of $H$. portulacoides with similar weights were randomly distributed into 20 hydroponic units, at a density of 10 plants per unit. Plants were inserted in the holes by the roots and fixed in place at the lower level of the stem using natural cotton.

The experiment consisted in 4 treatment solutions (including a control) and 5 replicate units $(n=5)$. The basis for the treatment solutions was an artificial seawater produced by mixing sea salts (Red Sea salt, Red Sea Aquatics, Cheddar, UK) with tap water purified by reverse-osmosis (V2Pure 360 RO System, TMC, Hertfordshirem UK) at a salinity of $20 \mathrm{ppt}$. At this salinity, the minerals $\mathrm{Ca}, \mathrm{Mg}$ and $\mathrm{K}$ in the base solution are at a concentration of 235-248 $\mathrm{mg} \mathrm{L}^{-1} \mathrm{Ca}, 703-742 \mathrm{mg} \mathrm{L}^{-1} \mathrm{Mg}$ and 213-226 $\mathrm{mg} \mathrm{L}^{-1} \mathrm{~K}$, according to information provided by the manufacturer. The control solution was the modified Hoagland's solution described above. The low-, medium- and high-input treatments consisted on modified versions of the control, where only nitrogen $(\mathrm{N})$ and phosphorous $(\mathrm{P})$ were adjusted, to mimic aquaculture-like effluents. Nomenclature and concentrations of $\mathrm{N}$ and $\mathrm{P}$ are as follows: $[\mathrm{N}, \mathrm{P}]_{\text {low }}=\left[6 \mathrm{mg} \mathrm{N} \mathrm{L}^{-1}, 0.8 \mathrm{mg} \mathrm{P} \mathrm{L}^{-1}\right] ;[\mathrm{N}, \mathrm{P}]_{\text {med }}=\left[20 \mathrm{mg} \mathrm{N} \mathrm{L}^{-1}, 3.0 \mathrm{mg} \mathrm{P} \mathrm{L}^{-1}\right] ;[\mathrm{N}, \mathrm{P}]_{\text {high }}=\left[100 \mathrm{mg} \mathrm{N} \mathrm{L}^{-1}\right.$, $\left.6.0 \mathrm{mg} \mathrm{P} \mathrm{L}^{-1}\right]$; Control $=\left[56 \mathrm{mg} \mathrm{N} \mathrm{L}^{-1}, 15.5 \mathrm{mg} \mathrm{P} \mathrm{L}^{-1}\right]$. For a detailed molecular and elemental composition of each treatment please see the supplementary Table S1 in the Supplementary Material available online. The solutions within each unit were continuously aerated with a small aerator to keep oxygen levels high and units were refilled with reverse-osmosis water as needed, to compensate for evapotranspiration. The treatment solutions were renewed weekly, as the retention time for nutrient extraction was set to one week. At the end of the growth trial, the leaves of individual plants were cut out, pooled by hydroponic unit and stored at $-80^{\circ} \mathrm{C}$ until further analysis. Water temperature and $\mathrm{pH}$ were measured regularly with a multi-parameter water quality meter and photosynthetically active radiation (PAR) was measured with a spherical micro quantum sensor (US-SQS/L, Heinz Walz GmbH, Pfullingen, Germany). Average values recorded at the end of each week, before renewal of treatment solutions, are presented as supplementary Table S2.

Analytical methods. Reagents. HPLC grade chloroform, methanol and acetonitrile were obtained from Fisher Scientific Ltd. (Loughborough, UK). Lipid internal standards 1,2-dimyristoyl-sn-glycero3-phosphate (dMPA), 1,2-dimyristoyl-sn-glycero-3-phosphocholine (dMPC), 1,2-dimyristoyl-sn-glycero-3-p hosphoethanolamine (dMPE), 1,2-dimyristoyl-sn-glycero-3-phospho-(10-rac-glycerol) (dMPG), 1,2-dipalmitoyl-sn-glycero-3-phosphatidylinositol (dPPI) and 1-nonadecanoyl-2-hydroxy-sn-glycero-3 -phosphocholine (LPC) were purchased from Avanti Polar Lipids, Inc. (Alabaster, AL). Milli-Q water (Synergy, Millipore Corporation, Billerica, MA, USA) was produced when ultrapure water was necessary. All other reagents were purchased from major commercial sources.

Leaves lipid extraction. Total lipids were extracted according to the method proposed by Bligh \& Dyer (1959) ${ }^{95}$, modified for seaweeds and halophytes ${ }^{22} .3 .75 \mathrm{~mL}$ of chloroform: methanol $(1: 2, \mathrm{v} / \mathrm{v})$ were added to $100 \mathrm{mg}$ of freeze-dried and grounded leaves followed by 2 -minutes vortex stirring and 1-minute sonication. Samples were then incubated on an orbital shaker for $2.5 \mathrm{~h}$, on ice. The homogenates were centrifuged at $2000 \mathrm{rpm}$ for 10 -minutes. The chloroform: methanol extraction followed by centrifugation was repeated twice to improve extraction efficiency. After extraction, $2.3 \mathrm{~mL}$ of ultrapure water was added to each supernatant, stirred on the vortex and centrifuged at $2000 \mathrm{rpm}$ for 10-minutes. Two liquid phases originate and the inferior organic phase, which contains the lipids, was recovered and dried under a stream of nitrogen gas. Each dried extract was dissolved in $600 \mu \mathrm{L}$ of chloroform and transferred to dark vials. Lipid extracts were dried under nitrogen gas, weighed (for 'total lipid' calculation) and stored at $-20^{\circ} \mathrm{C}$ prior to LC $-\mathrm{MS}$ analysis.

Quantification of phospholipids. Quantification of the total phospholipid content was achieved by using the protocol by Bartlett and Lewis (1970 $)^{96}$. First, in glass tubes, $125 \mu \mathrm{l}$ of percloric acid $(70 \% \mathrm{v} / \mathrm{v})$ was added to dried lipid extracts and the mixtures were incubated during 40 minutes at $170^{\circ} \mathrm{C}$. In the meantime, standards were prepared, also in glass tubes, using 0.1 to $2 \mu \mathrm{g}$ of phosphorous. After, $825 \mu \mathrm{l}$ of ultrapure water, $125 \mu \mathrm{l}$ of ammonium molybdate $(2.5 \% \mathrm{v} / \mathrm{v})$ and $125 \mu \mathrm{l}$ of ascorbic acid $(10 \% \mathrm{v} / \mathrm{v})$ were added to each sample and standards. All tubes were then vortexed. Tubes were incubated in water bath at $100^{\circ} \mathrm{C}$ for 10 minutes and transferred to ice to cool down. Absorbance of samples and standards were measured at $797 \mathrm{~nm}$ using a microplate reader (Multiskan GO, Thermo Scientific, Hudson, NH, USA). 
Quantification of glycolipids. Quantification of the total glycolipid content was achieved using the orcinol assay, as done in our lab ${ }^{25,97}$. First, an orcinol solution $(0.2 \% \mathrm{v} / \mathrm{v}$ in $70 \%$ sulfuric acid) was prepared and $1 \mathrm{~mL}$ was added to tubes with $\mathrm{N}_{2}$-dried lipid extract samples. Tubes were heated at $80^{\circ} \mathrm{C}$ for 20 minutes and transferred to ice to cool down. Absorbance of samples and standards were measured at $505 \mathrm{~nm}$ using a microplate reader (Multiskan GO, Thermo Scientific, Hudson, NH, USA). The concentration of glucose was calculated by comparing the data with those of glucose standards (between $0-50 \mu \mathrm{g}$ prepared from an aqueous solution containing $2 \mathrm{mg} \mathrm{mL}^{-1} \mathrm{of}^{\circ}$ glucose and following the same procedure as experimental samples).

Analysis of polar lipids by high resolution LC-MS and MS/MS. The polar lipids from $H$. portulacoides leaves were analyzed by high - performance LC (HPLC) system (Thermo Scientific Accela, Thermo Fisher Scientific, USA) with an autosampler coupled online to the Q-Exactive ${ }^{\circledR}$ mass spectrometer with Orbitrap ${ }^{\circledR}$ technology following the method previously used for halophyte lipid analysis ${ }^{22}$. The solvent system consisted of two mobile phases: mobile phase A [acetonitrile:methanol:water 50:25:25 (v/v/v) with $1 \mathrm{mM}$ ammonium acetate] and mobile phase B [acetonitrile:methanol 60:40 (v/v) with $1 \mathrm{mM}$ ammonium acetate]. Initially, 0\% of mobile phase A was held isocratically for 8 minutes, followed by a linear increase to $60 \%$ of A within 7 minutes and a maintenance period of 15 minutes, returning to the initial conditions within 10 minutes. A volume of $5 \mu \mathrm{L}$ of each sample containing $20 \mu \mathrm{g}$ of lipid extract, a volume of $4 \mu \mathrm{L}$ of internal standards mix (dMPA $-0.02 \mu \mathrm{g} \mathrm{g}^{-1}$; $\mathrm{dMPC}-0.005 \mu \mathrm{gg}^{-1}$, $\mathrm{dMPE}-0.005 \mu \mathrm{g} \mu \mathrm{g}^{-1}$, dMPG $-0.003 \mu \mathrm{g} \mu \mathrm{g}^{-1}$, dPPI $\left.-0.02 \mu \mathrm{g} \mu \mathrm{g}^{-1}, \mathrm{LPC}-0.005 \mu \mathrm{gg}^{-1}\right)$ and $91 \mu \mathrm{L}$ of mobile phase B were pipetted and introduced into the Ascentis ${ }^{\circledR} \mathrm{Si} \mathrm{column}(15 \mathrm{~cm} \times 1 \mathrm{~mm}, 3 \mu \mathrm{m}$, Sigma-Aldrich $)$ with a flow rate of $40 \mu \mathrm{L} \mathrm{min}^{-1}$ at $30^{\circ} \mathrm{C}$. The mass spectrometer with Orbitrap ${ }^{\circledR}$ technology was operated in simultaneous positive (electrospray voltage $3.0 \mathrm{kV}$ ) and negative (electrospray voltage $-2.7 \mathrm{kV}$ ) modes at a resolution of 70,000 and AGC target of $1 \mathrm{e} 6$, the capillary temperature was $250^{\circ} \mathrm{C}$ and the sheath gas flow was $15 \mathrm{U}$. In MS/MS experiments, a resolution of 17,500 and AGC target of $1 \mathrm{e} 5$ was used and the cycles consisted of one full scan mass spectrum and ten data-dependent MS/ MS scans, repeated continuously throughout the experiments with a dynamic exclusion of 60 seconds and intensity threshold of $1 \mathrm{e} 4$. Normalized collision energy ${ }^{\mathrm{TM}}$ (CE) ranged between 25 , 30 and $35 \mathrm{eV}$. MZmine 2.27 software was used to process MS raw data and identify lipid species by mass accuracy from high resolution MS data. Thermo Xcalibur 3.0.63 software was used to analyze the chromatograms and MS/ MS spectra, to confirm lipid species identity and discriminate their fatty-acid composition. The classes lysophosphatidylethanolamine (LPE), phosphatidic acid (PA), phosphatidylethanolamine (PE), phosphatidylglycerol (PG), phosphatidylinositol (PI) and sulfoquinovosyldiacylglycerol (SQDG) were detected as anionized adducts of $[\mathrm{M}-\mathrm{H}]^{-}$; digalactosyldiacylglycerol (DGDG), monogalactosyldiacylglycerol (MGDG) and monogalactosylmonoacylglycerol (MGMG) were detected as cationized adducts of $\left[\mathrm{N}+\mathrm{NH}_{4}\right]^{+}$; and lysophosphatidylcholine (LPC) and phosphatidylcholine (PC) were detected as cationized adducts of $[\mathrm{M}+\mathrm{H}]^{+}$. The FA composition of PCs and LPCs were identified by analysis of the MS/MS of anionized adducts of acetate $[\mathrm{M}+\mathrm{Ac}]^{-}$, which detects the carboxylate anions $\mathrm{R}^{-\mathrm{COO}^{-}}$that allow the determination of the fatty acyl composition. The dataset with the peak intensities, normalized to internal standards, is available online in the spreadsheet "Supplementary Dataset $1 "$.

Statistical analysis. Statistical analysis was performed using R (v3.4.3) in combination with RStudio (v1.1.463) and MetaboAnalyst (v4.0) ${ }^{98}$. Prior to analysis, the lipidomic dataset was normalized by dividing peak-intensity values of each molecular species with the peak-intensity of their respective internal standard (Supplementary Dataset 1). Secondly datasets were created for each lipid class, where the relative abundance of each molecular species was computed for each replicate (Supplementary Dataset 2).

Prior to the multivariate analysis, data normalization procedures - log-transformation followed by auto-scaling - were employed to decrease the influence of high-concentration metabolites and increase the statistical strength of low-concentration metabolites. Both unsupervised (Principal Components Analysis - PCA) and supervised (Partial Least Squares Discriminant Analysis - PLS-DA) methods were used.

The univariate analysis consisted on the analysis of variance, using the non-parametric Kruskal-Wallis test, of species i) peak-intensities and ii) relative abundance within each class. Post-hoc Dunn's test was used for pairwise comparisons and the Benjamini-Hochberg method was used to control for type-I errors ${ }^{99}$. Significant differences were assumed at a critical p-value $<0,05$.

\section{Data availability}

All data generated or analyzed during this study are included in this published article and its Supplementary Material files.

Received: 11 June 2019; Accepted: 27 March 2020;

Published online: 20 April 2020

\section{References}

1. Flowers, T. J., Hajibagheri, M. A. \& Clipson, N. J. W. Halophytes. The Quarterly Review of Biology 61, 313-337 (1986).

2. Flowers, T. J. \& Colmer, T. D. Salinity tolerance in halophytes*. New Phytologist 179, 945-963 (2008).

3. Flowers, T. J. \& Colmer, T. D. Plant salt tolerance: adaptations in halophytes. Ann. Bot. 115, 327-331 (2015)

4. Panta, S. et al. Halophyte agriculture: Success stories. Environmental and Experimental Botany 107, 71-83 (2014)

5. Loescher, W., Chan, Z. \& Grumet, R. Options for Developing Salt-tolerant Crops. HortScience 46, 1085-1092 (2011).

6. Mishra, A. \& Tanna, B. Halophytes: Potential Resources for Salt Stress Tolerance Genes and Promoters. Front. Plant Sci. 8, (2017).

7. Zhang, M. et al. Functional Identification of Salt-Stress-Related Genes Using the FOX Hunting System from Ipomoea pes-caprae. International Journal of Molecular Sciences 19, 3446 (2018).

8. Buhmann, A. \& Papenbrock, J. An economic point of view of secondary compounds in halophytes. Functional Plant Biol. 40, 952-967 (2013). 
9. Ventura, Y. \& Sagi, M. Halophyte crop cultivation: The case for Salicornia and Sarcocornia. Environmental and Experimental Botany 92, 144-153 (2013)

10. Maciel, E. et al. Bioprospecting of Marine Macrophytes Using MS-Based Lipidomics as a New Approach. Mar Drugs 14 (2016).

11. Barreira, L. et al. Halophytes: Gourmet food with nutritional health benefits? Journal of Food Composition and Analysis 59, 35-42 (2017).

12. Abd El-Hack, M. E. et al. Towards saving freshwater: halophytes as unconventional feedstuffs in livestock feed: a review. Environ Sci Pollut Res 25, 14397-14406 (2018).

13. Custódio, M., Villasante, S., Cremades, J., Calado, R. \& Lillebø, A. I. Unravelling the potential of halophytes for marine integrated multi-trophic aquaculture (IMTA) - a perspective on performance, opportunities and challenges. Aquaculture Environment Interactions 9, 445-460 (2017).

14. Troell, M. et al. Ecological engineering in aquaculture - Potential for integrated multi-trophic aquaculture (IMTA) in marine offshore systems. Aquaculture 297, 1-9 (2009).

15. Barrington, K., Ridler, N., Chopin, T., Robinson, S. \& Robinson, B. Social aspects of the sustainability of integrated multi-trophic aquaculture. Aquacult Int 18, 201-211 (2010).

16. Fang, J., Zhang, J., Xiao, T., Huang, D. \& Liu, S. Integrated multi-trophic aquaculture (IMTA) in Sanggou Bay, China. Aquacult. Environ. Interact. 8, 201-205 (2016).

17. Granada, L., Sousa, N., Lopes, S. \& Lemos, M. F. L. Is integrated multitrophic aquaculture the solution to the sectors' major challenges? - a review. Reviews in Aquaculture 8, 283-300 (2016).

18. Boughalleb, F. \& Denden, M. Physiological and Biochemical Changes of Two Halophytes, Nitraria retusa (Forssk.) and Atriplex halimus (L.) Under Increasing Salinity. Agricultural J. 6, 327-339 (2011).

19. Ksouri, R. et al. Medicinal halophytes: potent source of health promoting biomolecules with medical, nutraceutical and food applications. Critical Reviews in Biotechnology 32, 289-326 (2012).

20. Ksouri, W. M. et al. LC-ESI-TOF-MS identification of bioactive secondary metabolites involved in the antioxidant, antiinflammatory and anticancer activities of the edible halophyte Zygophyllum album Desf. Food Chemistry 139, 1073-1080 (2013).

21. Rodrigues, M. J. et al. Maritime Halophyte Species from Southern Portugal as Sources of Bioactive Molecules. Marine Drugs 12, 2228-2244 (2014).

22. Maciel, E. et al. Polar lipidome profiling of Salicornia ramosissima and Halimione portulacoides and the relevance of lipidomics for the valorization of halophytes. Phytochemistry 153, 94-101 (2018).

23. Zengin, G., Aumeeruddy-Elalfi, Z., Mollica, A., Yilmaz, M. A. \& Mahomoodally, M. F. In vitro and in silico perspectives on biological and phytochemical profile of three halophyte species-A source of innovative phytopharmaceuticals from nature. Phytomedicine 38, 35-44 (2018).

24. da Costa, E. et al. Decoding bioactive polar lipid profile of the macroalgae Codium tomentosum from a sustainable IMTA system using a lipidomic approach. Algal. Research 12, 388-397 (2015).

25. Da Costa, E. et al. Valorization of Lipids from Gracilaria sp. through Lipidomics and Decoding of Antiproliferative and AntiInflammatory Activity. Marine Drugs 15, 62 (2017).

26. Melo, T. et al. Lipidomics as a new approach for the bioprospecting of marine macroalgae - Unraveling the polar lipid and fatty acid composition of Chondrus crispus. Algal. Research 8, 181-191 (2015).

27. da Costa, E. et al. Lipidomic Signatures Reveal Seasonal Shifts on the Relative Abundance of High-Valued Lipids from the Brown Algae Fucus vesiculosus. Marine Drugs 17, 335 (2019).

28. Cortés-Sánchez, A., de, J., Hernández-Sánchez, H. \& Jaramillo-Flores, M. E. Biological activity of glycolipids produced by microorganisms: New trends and possible therapeutic alternatives. Microbiological Research 168, 22-32 (2013).

29. Küllenberg, D., Taylor, L. A., Schneider, M. \& Massing, U. Health effects of dietary phospholipids. Lipids in Health and Disease 11, 3 (2012).

30. Horn, P. J. \& Benning, C. The plant lipidome in human and environmental health. Science 353, 1228-1232 (2016).

31. Chung, S.-Y. et al. Administration of Phosphatidylcholine Increases Brain Acetylcholine Concentration and Improves Memory in Mice with Dementia. J Nutr 125, 1484-1489 (1995).

32. Jäger, R., Purpura, M. \& Kingsley, M. Phospholipids and sports performance. Journal of the International Society of Sports Nutrition 4, 5 (2007).

33. Burri, L., Hoem, N., Banni, S. \& Berge, K. Marine omega-3 phospholipids: metabolism and biological activities. Int J Mol Sci 13, 15401-15419 (2012).

34. Lopes, G., Daletos, G., Proksch, P., Andrade, P. B. \& Valentão, P. Anti-Inflammatory Potential of Monogalactosyl Diacylglycerols and a Monoacylglycerol from the Edible Brown Seaweed Fucus spiralis Linnaeus. Mar Drugs 12, 1406-1418 (2014).

35. Schneider, G. et al. Novel pleiotropic effects of bioactive phospholipids in human lung cancer metastasis. Oncotarget 8, 58247-58263 (2017).

36. Sun, N., Chen, J., Wang, D. \& Lin, S. Advance in food-derived phospholipids: Sources, molecular species and structure as well as their biological activities. Trends in Food Science \&. Technology 80, 199-211 (2018).

37. Sui, N., Li, M., Li, K., Song, J. \& Wang, B.-S. Increase in unsaturated fatty acids in membrane lipids of Suaeda salsa L. enhances protection of photosystem II under high salinity. Photosynthetica 48, 623-629 (2010).

38. Isca, V. M. S., Seca, A. M. L., Pinto, D. C. G. A., Silva, H. \& Silva, A. M. S. Lipophilic profile of the edible halophyte Salicornia ramosissima. Food Chem. 165, 330-336 (2014).

39. Kostetsky, E. Y., Goncharova, S. N., Sanina, N. M. \& Shnyrov, V. L. Season influence on lipid composition of marine macrophytes. Botanica Marina 47, (2004).

40. Stengel, D. B., Connan, S. \& Popper, Z. A. Algal chemodiversity and bioactivity: sources of natural variability and implications for commercial application. Biotechnol. Adv. 29, 483-501 (2011).

41. Hou, Q., Ufer, G. \& Bartels, D. Lipid signalling in plant responses to abiotic stress. Plant Cell Environ. 39, 1029-1048 (2016).

42. Lin, Y.-F. et al. Performance of a constructed wetland treating intensive shrimp aquaculture wastewater under high hydraulic loading rate. Environmental Pollution 134, 411-421 (2005).

43. Webb, J. M. et al. The effect of halophyte planting density on the efficiency of constructed wetlands for the treatment of wastewater from marine aquaculture. Ecological Engineering 61, 145-153 (2013).

44. Buhmann, A. K., Waller, U., Wecker, B. \& Papenbrock, J. Optimization of culturing conditions and selection of species for the use of halophytes as biofilter for nutrient-rich saline water. Agricultural Water Management 149, 102-114 (2015).

45. Quintã, R., Santos, R., Thomas, D. N. \& Le Vay, L. Growth and nitrogen uptake by Salicornia europaea and Aster tripolium in nutrient conditions typical of aquaculture wastewater. Chemosphere 120, 414-421 (2015).

46. Waller, U. et al. Integrated multi-trophic aquaculture in a zero-exchange recirculation aquaculture system for marine fish and hydroponic halophyte production. Aquacult Int 23, 1473-1489 (2015).

47. Patel, M. K., Pandey, S., Brahmbhatt, H. R., Mishra, A. \& Jha, B. Lipid content and fatty acid profile of selected halophytic plants reveal a promising source of renewable energy. Biomass and Bioenergy 124, 25-32 (2019).

48. Lu, D. et al. Nutritional characterization and changes in quality of Salicornia bigelovii Torr. during storage. LWT - Food Science and Technology 43, 519-524 (2010).

49. Ben Hamed, K., Ben Youssef, N., Ranieri, A., Zarrouk, M. \& Abdelly, C. Changes in content and fatty acid profiles of total lipids and sulfolipids in the halophyte Crithmum maritimum under salt stress. J. Plant Physiol. 162, 599-602 (2005). 
50. Costa, C. S. B. et al. Extraction and characterization of lipids from Sarcocornia ambigua meal: a halophyte biomass produced with shrimp farm effluent irrigation. Anais da Academia Brasileira de Ciências 86, 935-943 (2014).

51. Kulis, M. J. et al. Extraction and Characterization of Lipids From Salicornia Virginica and Salicornia Europaea. 16 (2010).

52. Duarte, B. et al. Halophyte fatty acids as biomarkers of anthropogenic-driven contamination in Mediterranean marshes: Sentinel species survey and development of an integrated biomarker response (IBR) index. Ecological Indicators 87, 86-96 (2018).

53. Ventura, Y. et al. Effect of seawater concentration on the productivity and nutritional value of annual Salicornia and perennial Sarcocornia halophytes as leafy vegetable crops. Scientia Horticulturae 128, 189-196 (2011).

54. Harris, W. Omega-6 and omega-3 fatty acids: partners in prevention. Curr Opin Clin Nutr Metab Care 13, 125-129 (2010).

55. Simopoulos, A. P. Importance of the omega-6/omega-3 balance in health and disease: evolutionary aspects of diet. World Rev Nutr Diet 102, 10-21 (2011).

56. Husted, K. S. \& Bouzinova, E. V. The importance of n-6/n-3 fatty acids ratio in the major depressive disorder. Medicina (Kaunas) 52, 139-147 (2016)

57. Liu, A. G. et al. A healthy approach to dietary fats: understanding the science and taking action to reduce consumer confusion. Nutrition Journal 16, 53 (2017).

58. Shahidi, F. \& Ambigaipalan, P. Omega-3 Polyunsaturated Fatty Acids and Their Health Benefits. Annu Rev Food Sci Technol 9 , 345-381 (2018).

59. Rozentsvet, O. A. et al. Structural and functional organization of the photosynthetic apparatus in halophytes with different strategies of salt tolerance. Photosynthetica 54, 405-413 (2016).

60. Asilbekova, D. T., Tursunkhodzhaeva, F. M. \& Nigmatullaev, A. M. Lipids from Halostachys caspica and Halocharis hispida. Chem Nat Compd 45, 322-324 (2009).

61. Rozentsvet, O. A., Nesterov, V. N. \& Bogdanova, E. S. Membrane-forming lipids of wild halophytes growing under the conditions of Prieltonie of South Russia. Phytochemistry 105, 37-42 (2014).

62. Jouhet, J. et al. Phosphate deprivation induces transfer of DGDG galactolipid from chloroplast to mitochondria. J Cell Biol 167, 863-874 (2004)

63. Kelly, A. A. \& Dörmann, P. Green light for galactolipid trafficking. Curr. Opin. Plant Biol. 7, 262-269 (2004).

64. Benning, C. \& Ohta, H. Three Enzyme Systems for Galactoglycerolipid Biosynthesis Are Coordinately Regulated in Plants. J. Biol. Chem. 280, 2397-2400 (2005).

65. Hartel, H., Dormann, P. \& Benning, C. DGD1-Independent Biosynthesis of Extraplastidic Galactolipids after Phosphate Deprivation in Arabidopsis. Proceedings of the National Academy of Sciences of the United States of America 97, 10649-10654 (2000).

66. Okazaki, Y. et al. A new class of plant lipid is essential for protection against phosphorus depletion. Nat. Commun. 4, 1-10 (2013).

67. Andersson, M. X., Stridh, M. H., Larsson, K. E., Liljenberg, C. \& Sandelius, A. S. Phosphate-deficient oat replaces a major portion of the plasma membrane phospholipids with the galactolipid digalactosyldiacylglycerol. FEBS Lett. 537, 128-132 (2003).

68. Okazaki, Y., Takano, K. \& Saito, K. Lipidomic analysis of soybean leaves revealed tissue-dependent difference in lipid remodeling under phosphorus-limited growth conditions. Plant Biotechnol (Tokyo) 34, 57-63 (2017).

69. Bellinger, B. J. \& Mooy, B. A. S. V. Nonphosphorus Lipids in Periphyton Reflect Available Nutrients in the Florida Everglades, Usa1. Journal of Phycology 48, 303-311 (2012).

70. Kumari, P., Kumar, M., Reddy, C. R. K. \& Jha, B. Nitrate and phosphate regimes induced lipidomic and biochemical changes in the intertidal macroalga Ulva lactuca (Ulvophyceae, Chlorophyta). Plant Cell Physiol. 55, 52-63 (2014).

71. Kalisch, B., Dörmann, P. \& Hölzl, G. DGDG and Glycolipids in Plants and Algae. In Lipids in Plant and Algae Development (eds. Nakamura, Y. \& Li-Beisson, Y.) 51-83 doi:10.1007/978-3-319-25979-6_3 (Springer International Publishing, 2016).

72. Moreau, P. et al. Lipid trafficking in plant cells. Progress in Lipid Research 37, 371-391 (1998).

73. Hölzl, G. \& Dörmann, P. Structure and function of glycoglycerolipids in plants and bacteria. Progress in Lipid Research 46, 225-243 (2007).

74. Tóth, V. R., Mészáros, I., Veres, S. \& Nagy, J. Effects of the available nitrogen on the photosynthetic activity and xanthophyll cycle pool of maize in field. Journal of Plant Physiology 159, 627-634 (2002).

75. Damiani, M. C., Popovich, C. A., Constenla, D. \& Leonardi, P. I. Lipid analysis in Haematococcus pluvialis to assess its potential use as a biodiesel feedstock. Bioresource Technology 101, 3801-3807 (2010).

76. Goncalves, E. C., Johnson, J. V. \& Rathinasabapathi, B. Conversion of membrane lipid acyl groups to triacylglycerol and formation of lipid bodies upon nitrogen starvation in biofuel green algae Chlorella UTEX29. Planta 238, 895-906 (2013).

77. Wang, X., Shen, Z. \& Miao, X. Nitrogen and hydrophosphate affects glycolipids composition in microalgae. Sci. Rep. 6, 1-9 (2016).

78. Liu, Z. et al. Photosynthetic Characteristics and Chloroplast Ultrastructure of Summer Maize Response to Different Nitrogen Supplies. Front. Plant Sci. 9, (2018).

79. Dubots, E. et al. Role of phosphatidic acid in plant galactolipid synthesis. Biochimie 94, 86-93 (2012).

80. Pant, B. D. et al. The transcription factor PHR1 regulates lipid remodeling and triacylglycerol accumulation in Arabidopsis thaliana during phosphorus starvation. J. Exp. Bot. 66, 1907-1918 (2015).

81. Rennenberg, H. \& Schmidt, S. Perennial lifestyle-an adaptation to nutrient limitation? Tree Physiol 30, 1047-1049 (2010).

82. Friedman, J. \& Rubin, M. J. All in good time: understanding annual and perennial strategies in plants. Am. J. Bot. 102, 497-499 (2015).

83. Ticconi, C. A., Delatorre, C. A. \& Abel, S. Attenuation of Phosphate Starvation Responses by Phosphite in Arabidopsis. Plant Physiology 127, 963-972 (2001).

84. Lambers, H., Shane, M. W., Cramer, M. D., Pearse, S. J. \& Veneklaas, E. J. Root structure and functioning for efficient acquisition of phosphorus: Matching morphological and physiological traits. Ann. Bot. 98, 693-713 (2006).

85. Yang, X. J. \& Finnegan, P. M. Regulation of phosphate starvation responses in higher plants. Ann. Bot. 105, 513-526 (2010).

86. Plaxton, W. C. \& Tran, H. T. Metabolic Adaptations of Phosphate-Starved Plants. Plant Physiology 156, 1006-1015 (2011).

87. Karthikeyan, A. S. et al. Arabidopsis thaliana mutant lpsi reveals impairment in the root responses to local phosphate availability. Plant Physiology and Biochemistry 77, 60-72 (2014).

88. Marques, B., Calado, R. \& Lillebø, A. I. New species for the biomitigation of a super-intensive marine fish farm effluent: Combined use of polychaete-assisted sand filters and halophyte aquaponics. Science of The Total Environment 599-600, 1922-1928 (2017).

89. Castro, R. et al. Accumulation, distribution and cellular partitioning of mercury in several halophytes of a contaminated salt marsh. Chemosphere 76, 1348-1355 (2009).

90. Cabrita, M. T. et al. Mercury mobility and effects in the salt-marsh plant Halimione portulacoides: Uptake, transport, and toxicity and tolerance mechanisms. Science of The Total Environment 650, 111-120 (2019).

91. Kümmerer, K. Antibiotics in the aquatic environment - A review - Part I. Chemosphere 75, 417-434 (2009).

92. Rai, P. K., Lee, S. S., Zhang, M., Tsang, Y. F. \& Kim, K.-H. Heavy metals in food crops: Health risks, fate, mechanisms, and management. Environment International 125, 365-385 (2019).

93. Alexander, K. A. et al. The implications of aquaculture policy and regulation for the development of integrated multi-trophic aquaculture in Europe. Aquaculture 443, 16-23 (2015).

94. Stévant, P., Rebours, C. \& Chapman, A. Seaweed aquaculture in Norway: recent industrial developments and future perspectives. Aquacult Int 25, 1373-1390 (2017).

95. Bligh, E. G. \& Dyer, W. J. A rapid method of total lipid extraction and purification. Can. J. Biochem. Physiol. 37, 911-917 (1959). 
96. Bartlett, E. M. \& Lewis, D. H. Spectrophotometric determination of phosphate esters in the presence and absence of orthophosphate. Analytical Biochemistry 36, 159-167 (1970).

97. Quantitative estimation | Cyberlipid. http://cyberlipid.gerli.com/techniques-of-analysis/analysis-of-complex-lipids/ glycoglycerolipid-analysis/quantitative-estimation/.

98. Chong, J. et al. MetaboAnalyst 4.0: towards more transparent and integrative metabolomics analysis. Nucleic Acids Res 46, W486-W494 (2018).

99. Checa, A., Bedia, C. \& Jaumot, J. Lipidomic data analysis: Tutorial, practical guidelines and applications. Analytica Chimica Acta 885, 1-16 (2015).

\section{Acknowledgements}

We acknowledge FCT/MEC for the financial support to M. Custódio through a PhD grant (PD/BD/127990/2016), to QOPNA-LAQV (UID/QUI/00062/2019), to the Portuguese Mass Spectrometry Network (LISBOA-01-0145FEDER-402-022125) and to CESAM (UIDB/50017/2020+UIDP/50017/2020) through national funds and cofunding by FEDER, within the PT2020 Partnership Agreement and Compete 2020. This work was also supported by the Integrated Program of SR\&TD "Smart Valorization of Endogenous Marine Biological Resources Under a Changing Climate” (Centro-01-0145-FEDER-000018), co-funded by Centro 2020 program, Portugal 2020 and European Union, through the European Regional Development Fund, and by the project "AquaMMIn Development and validation of a modular integrated multitrophic aquaculture system for marine and brackish water species" (MAR-02.01.01-FEAMP-0038) co-funded by Portugal 2020 and the European Union through Mar2020, the Operational Programme (OP) for the European Maritime and Fisheries Fund (EMFF) in Portugal. This is a contribution of the Marine Lipidomic Laboratory (MARLL).

\section{Author contributions}

M.C., M.R.D., A.I.L. and R.C. conceived and designed the experiment; M.C. and E.M. performed the experiment; M.C., E.M. and M.R.D. analyzed the data; E.M., M.R.D., A.I.L. and R.C. contributed with reagents/materials/ analysis tools; M.C. lead the manuscript writing and all authors reviewed the manuscript.

\section{Competing interests}

The authors declare no competing interests.

\section{Additional information}

Supplementary information is available for this paper at https://doi.org/10.1038/s41598-020-63551-1.

Correspondence and requests for materials should be addressed to M.C. or R.C.

Reprints and permissions information is available at www.nature.com/reprints.

Publisher's note Springer Nature remains neutral with regard to jurisdictional claims in published maps and institutional affiliations.

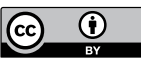

Open Access This article is licensed under a Creative Commons Attribution 4.0 International License, which permits use, sharing, adaptation, distribution and reproduction in any medium or format, as long as you give appropriate credit to the original author(s) and the source, provide a link to the Creative Commons license, and indicate if changes were made. The images or other third party material in this article are included in the article's Creative Commons license, unless indicated otherwise in a credit line to the material. If material is not included in the article's Creative Commons license and your intended use is not permitted by statutory regulation or exceeds the permitted use, you will need to obtain permission directly from the copyright holder. To view a copy of this license, visit http://creativecommons.org/licenses/by/4.0/.

(c) The Author(s) 2020 